Marquette University

e-Publications@Marquette

$1-20-2016$

Heterogeneity in the Preferences and ProEnvironmental Behavior of College Students: The Effects of Years on Campus, Demographics, and External Factors

Andrew G. Meyer

Marquette University, andrew.g.meyer@marquette.edu

NOTICE: this is the author's version of a work that was accepted for publication in Journal of Cleaner Production. Changes resulting from the publishing process, such as peer review, editing, corrections, structural formatting, and other quality control mechanisms may not be reflected in this document. Changes may have been made to this work since it was submitted for publication. A definitive version was subsequently published in Journal of Cleaner Production, Vol. 112, No. 4 (January 2016):

3451-3463. DOI. (C) 2016 Elsevier. Used with permission. 


\title{
Heterogeneity in the Preferences and Pro-Environmental Behavior of College Students: The Effects of Years on Campus, Demographics, and External Factors
}

\section{Andrew Meyer}

October 29, 2015

\begin{abstract}
Models from several social science fields have identified factors that lead to proenvironmental behavior. This research builds on those models by analyzing a survey completed by over 500 undergraduates at a US liberal arts university to examine the characteristics of students that are associated with more environmentally friendly behavior and quantify the desirability of different environmental initiatives. There is evidence that the probability of pro-environmental behavior substantially increases with each additional year that a student spends on campus. The magnitude of the effect is between 4 to 10 percentage points per year, depending on the specific behavior and empirical model. This contribution suggests that higher education impacts pro-environmental behavior and supports the notion that higher education institutions can play an important role in making societies more sustainable. Further, evidence is presented to suggest that this increase in pro-environmental behavior over one's college career is due to factors outside of the formal curriculum. This study also finds that females and ethnic/racial minorities engage in significantly higher levels of green behavior including recycling and double-sided printing. On average, students prefer sustainability initiatives related to energy conservation and recycling to other environmental programs but there is a great deal of heterogeneity in these preferences.
\end{abstract}

Keywords: higher education; sustainability; survey; pro-environmental behavior

* Andrew Meyer, Assistant Professor of Economics, Marquette University, Department of Economics, College of Business Administration, 606 N. 13 ${ }^{\text {th }}$ St, David Straz Hall, Room 581, Milwaukee, WI 53233. Email: andrew.g.meyer@marquette.edu 


\section{Introduction}

Many higher education institutions have implemented sustainability initiatives in recent years (Campbell-Arvai, 2015; Levy and Marans, 2012). Other institutions have faced roadblocks in incorporating sustainability but have an interest in making progress in this area (Larrán et al., 2015; Lidgren et al., 2006; Schmitt-Figueiró and Raufflet, 2015). ${ }^{1}$ Two main reasons have been cited as to why colleges and universities would be interested in driving pro-environmental changes; these relate to the mission of the university and possible recruitment benefits for admissions. Explanations related to the mission have received the most attention in the academic literature where it is noted that higher education recognizes that it has an important role in teaching sustainability as part of its larger mission to educate individuals and build a better future (Barth and Rieckmann, 2012; Ramos et al., 2015; Zilahy and Huisingh, 2009). If higher education is indeed effective in inducing change in students' pro-environmental behavior, all else equal, it logically follows that one should see the probability of pro-environmental behavior increase with the number of years spent on campus. However, present evidence of changes in pro-environmental behavior throughout the college experience is rather limited (Heyl et al., 2013; Vicente-Molina et al., 2013). There is some evidence that environmental attitudes improve with years spent on campus (Fernandez-Manzanal et al., 2007; Levine and Strube, 2012). But, it has been shown in several places that environmental attitudes or knowledge have only limited ability to explain pro-environmental behavior (Kollmuss and Agyeman, 2002; Scott and Willits, 1994).

\footnotetext{
${ }^{1}$ Lozano (2006) provides recommendations for universities seeking to adopt sustainable development principles and Lozano et al. (2015) documents the progress that has been made at universities around the world.
} 
To the author's knowledge, there are only a few studies that test for differences in pro-environmental behavior between students in different years of their college career. These studies both stem from data on Chilean students from specific majors and do not find any significant differences based upon year of study (Cerda et al., 2007; Heyl et al., 2013). Therefore, more work is needed on students of all types of majors and from different countries. Thus, the primary contribution of this study is to quantify how much the probability of pro-environmental behavior increases as a function of year in college for all types of majors at a United States university. Evidence on this relationship is important because it speaks to the important role that higher education can play in society.

Many papers examine the general association between education and proenvironmental concern or behavior. However, the criticism is that this relationship in the general population may not be causal because individuals choose their level of education and also choose how to behave with respect to the environment. Any personal characteristic that is omitted from the analysis and correlated with both level of education and proenvironmental behavior could be biasing the results. Thus, previous findings of a positive association between education level and pro-environmental behavior in the general population need not imply that additional years of college cause pro-environmental behavior to increase. Others have also noted that it is difficult to establish a causal link between education and pro-environmental behavior (Vicente-Molina et al., 2013; Zsóka et al., 2012). However, it is precisely this causal relationship that is of greater interest to institutes of higher education.

Meyer (2015) provides evidence that education does have a positive causal effect on pro-environmental behavior with instrumental variables methods, utilizing educational 
reforms in $20^{\text {th }}$ century Europe as the instrument. However, Meyer (2015) argues that these reforms most likely affected individuals at the lower end of the educational spectrum so the results are not directly applicable to college level education. In contrast, the present paper exclusively focuses on college students. The advantage of focusing on this group is that unobservable characteristics are not likely to differ substantially between college students in different years of their careers at the same institution.

The literature on pro-environmental behavior and sustainability has recognized that informal education may be just as important as the formal curriculum in fostering learning or behavioral change (Digby, 2012; Hopkinson et al., 2008). Supposing a positive impact of education on pro-environmental behavior, simply looking at the year in college cannot inform us as to which of these mechanisms is responsible. However, the mechanism matters because it could have implications for how institutes of higher education attempt to affect change. As a second contribution, this study addresses the mechanism by comparing across different majors to see if there is a differential effect of year in school on pro-environmental behavior. The rationale is that students in majors such as biology, ecology, or environmental studies would be exposed to more formal education on the environment. Thus, one should see increases in pro-environmental behavior from these students over and above that of students in other majors if formal education is the mechanism for change.

As for the second reason for driving pro-environmental change, in a competitive recruiting environment, institutes of higher education may logically decide to promote certain aspects of their environmental performance to attract students. For example, Princeton Review's recent "College Hopes and Worries Survey" finds that $62 \%$ of college 
applicants said that having information about a college's commitment to environmental issues would impact their decision to apply to a school (2014). Furthermore, Julian Dautremont-Smith from the Association for the Advancement of Sustainability in Higher Education (AASHE) writes that "the available evidence is consistent in suggesting that a significant, and likely growing, proportion of prospective students are making decisions about where to apply and attend based on campus sustainability performance" (2009). However, it is quite possible that certain environmental issues are more important to students than others. Therefore, as a minor contribution, this research quantifies the attractiveness of environmental programs on a residential university campus and explores factors that explain differences in program preferences. Furthermore, different segments of the student population may be more or less attracted to environmental promotion. Thus, as a final contribution, this analysis provides insight into which students are more environmentally focused by analyzing the characteristics of students that are associated with more extensive green behaviors.

Therefore, this research has three main aims: 1) test the hypothesis that additional years of education increase pro-environmental behavior, 2) quantify the desirability of various environmental initiatives in the eyes of students, and 3) explain heterogeneity in students' environmental preferences and pro-environmental behaviors and explore the associated implications for higher education institutions. To address these research questions, a survey of college students is conducted at a U.S. Midwestern liberal arts institution, Ohio Wesleyan University (hereafter OWU), including questions about environmental preferences and green behaviors. The paper proceeds with an overview of 
important related literature to provide some context prior to explaining the methods and results of the study.

\section{Related Literature and Context}

Social scientists have analyzed the determinants of pro-environmental behavior within a variety of disciplines including "economics, sociology, anthropology, and psychology" (Turaga et al., 2010). Main clusters of research are found within economics, where individual decisions are assumed to be made according to some definition of rational selfinterest, and psychology, where researchers focus on linking psychological or internal variables to behavior (Clark et al, 2003). Thus, economists tend to focus on "external conditions, such as income, price, and socio-economic characteristics, upon behavior" (Clark et al., 2003). In contrast, psychologists tend to focus on "values, beliefs, and attitudes... and recognize awareness, education, guilt, and persuasion” (Clark et al., 2003). It is not the intent of this study to test any specific theory of pro-environmental behavior. However, for context, it is useful to lay out some of the aspects of the psychological and economic models that attempt to explain pro-environmental behavior.

There are a variety of theoretical approaches within psychology and economics to study pro-environmental behavior. Moreover, two strands of literature from economics and psychology have begun to converge: voluntary provision of public goods from economics and theories of moral motivation from social psychology (Turaga et al., 2010). According to Turaga et al. (2010), norm-activation theory and value-belief-norms theory are two of the most "coherent, well-accepted, and empirically supported theories of moral motivation." Norm-activation theory has been used to explain pro-social behavior in general, including pro-environmental behavior (Turaga et al., 2010). Developed by 
Schwartz (1970, 1973, 1977), norm-activation theory maintains that an individual must first be aware of the consequences of one's actions for the welfare of other humans, feel personally responsible to take action, and then activate personally held moral norms. Value-belief-norms theory (Stern et al., 1993) extends Schwartz's norm-activation theory to include norms on self-interest and altruism toward nonhuman species (Turaga et al., 2010). In both of these models, it is crucial that an individual be aware of the consequences of one's action. It is clear to see how education, both formal and informal, could then be an important driver of pro-environmental behavior.

Kollmus and Agyeman (2002) review a range of psychological and sociological theoretical frameworks to explain the gap between environmental knowledge and proenvironmental behavior. They argue that all of the models have some validity in certain circumstances but that a model incorporating all of the factors from all of the models would lose most of its meaning. Nonetheless, they form a list of demographic factors, external factors, and internal factors that have been shown to influence pro-environmental behavior. Demographic factors include gender and years of education, although they note that "more education does not necessarily mean increased pro-environmental behavior" (Kollmuss and Agyeman, 2002). External factors include institutions, economic factors such as prices and incentives, and social and cultural factors. Internal factors include motivation, environmental knowledge, values, attitudes, environmental awareness, emotional involvement, locus of control, and responsibility and priorities.

In the economics literature, pro-environmental behavior is an example of a voluntary contribution to a public good (Clark et al., 2003). In the traditional model of a self-interested rational economic decision-maker, an individual has little incentive to 
contribute to a public good and would instead free-ride on the contributions of others (Turaga et al., 2010). Therefore, much of the theoretical work in economics has been devoted to formulating alternative models that can explain why a rational decision-maker would choose to contribute to a public good. Beginning with Andreoni (1990), this work incorporates various forms of altruism where individuals receive warm glow utility from contributing to the public good. That is, in these models, individuals contribute not because they are concerned with the aggregate level of the public good, but because it makes them feel good to do so. Models subsequent to Andreoni (1990) have identified prestige (Harbaugh, 1998), social approval (Holländer, 1990; Rege, 2004), and self-image (Brekke et al., 2003) as theoretical motivators for a self-interested individual to contribute to a public good. Thus, modern economic and psychological models have recognized the importance of both internal and external factors as determinants of pro-environmental behavior. As covered in the subsequent methods section, this study concentrates mainly on demographic and external factors because these are the factors that are readily observable to institutes of higher education.

As mentioned, gender is one demographic factor that appears to matter for proenvironmental behavior in the general population. Many studies have documented that women report stronger environmental concern than men (De Silva and Pownall, 2014; Eisler et al., 2003; Torger and García-Valiñas, 2007). ${ }^{2}$ This concern also appears to carry over to differences in behavior in a variety of contexts (Block et al., 2015; Brecard et al., 2009). Specific to college students, Vicente-Molina et al. (2013) find that male students in both emerging and advanced countries are less likely to exhibit pro-environmental behavior

\footnotetext{
${ }^{2}$ Zelezny et al. (2000) provide an early review of the literature.
} 
than their female counterparts. Likewise, education has been shown to correlate positively with environmental concern and/or pro-environmental behavior. Some examples covering the general population include Brecard et al. (2009), De Silva and Pownall (2014), and Klineberg et al. (1998). Examples specific to students include Levin and Strube (2012), Zsóka et al. (2012). ${ }^{3}$ Yet, these findings are not universal. For example, Ek and Söderholm (2008) find that neither gender nor education significantly explain one's support of green electricity. Schultz et al. (1995) notes that gender does not seem to play a role in explaining recycling behavior.

Other demographic/external factors appearing in the literature include race/ethnicity and income. Past studies regarding the effect of ethnicity on environmental attitude and behavior are mixed. For example, Jones (1998) finds that environmental concern and behavior is sometimes stronger for minorities than for whites but Johnson et al. (2004) and Zube and Pitt (1981) find that minorities may exhibit lower levels of environmentalism. Similarly, past studies find mixed results with respect to the effect of income on environmentalism with the conventional economic theory being that concern for the environment increases with income. For examples of positive estimates of the income elasticity of demand for environmental quality, see Kristrom and Riera (1996) and Zabel and Kiel (2000). Viscusi et al. (2011) provides an example of income having a positive relationship with recycling behavior. On the contrary, Ferreira and Moro (2013) do not find evidence that marginal willingness to pay for environmental quality increases with income in the context of a subjective well-being study. Similarly, De Silva and Pownall (2014) find no evidence that income affects environmental values. Overall,

\footnotetext{
${ }^{3}$ For a recent review of studies that focus on pro-environmental behavior, see Meyer (2015).
} 
empirical evidence agrees with the main theoretical predictions that both internal and external factors can be important.

\section{Methods}

A survey of OWU students was conducted in the fall of 2011 to investigate their environmental attitudes and behaviors and gain information about their environmental priorities, and assess how much they would be willing to pay to support a student green fee (a separate fee to support sustainability or pro-environmental projects). ${ }^{4}$ All students were contacted via email and asked to complete the survey online. The student population of OWU is approximately 1850 and 559 students completed the survey. This corresponds to approximately a $30 \%$ response rate. 515 of the 559 students are domestic students, with the remaining 44 responses representing international students. This analysis focuses on the domestic student responses because of the ability to link these to important explanatory variables that are not collected in the survey.

\subsection{Survey Description}

The first portion of the survey begins by asking students about their current environmental behaviors. Students are questioned about their environmental behaviors in several areas including recycling, energy use, double-sided printing, and involvement in environmental groups. Recycling questions include, "How often do you recycle your used paper?" and "How often do you use the recycling bins for other recyclables?" Students provide categorical responses to these two recycling questions. The five categories include, "always

\footnotetext{
${ }^{4}$ The green fee question is part of a larger research design and is analyzed in a separate paper.
} 
yes," "usually yes," "sometimes yes/sometimes no," "usually no," and "always no." Table 1 summarizes the responses to these two recycling questions.

[Table 1 about here]

Energy use is measured with the question, "Did you turn off the light the last time you walked out of an empty room?" Environmental involvement is gauged with, “Are you currently, or have you ever been involved in any environmental groups, environmental volunteer activities, or environmental donation projects?" The responses to these two questions are given in Table 2. Finally, students are asked, "Do you use the double printing option when you print in the library?" This question is quite interesting because there is no financial benefit for using the double-sided printing option. It costs the same per page to print single-sided or double-sided. ${ }^{5}$ Table 3 describes the responses to this question.

[Tables 2 and 3 about here]

The next section of the survey asks students about their opinions on different aspects of how to improve sustainability on campus. This section begins by asking about four broad categories: water waste, energy waste, recycling waste, and food waste. The survey instructs students to, "Please indicate your opinion on which aspects should receive highest and lowest priority. Please rank from $1=$ top priority to $4=4^{\text {th }}$ priority." Table 4 summarizes the results for this question. Energy waste appears to be the top priority for the majority of students, with recycling being the next most important area to students. Students see food waste and water waste as less important issues.

Students were then asked to rank a list of specific in-progress and potential projects from highest priority (1) to lowest priority (11). The list of projects is as follows: complete

\footnotetext{
${ }^{5}$ For example, the total charge is the same to the student whether 4 pages are printed on 4 separate pieces of paper or double-sided on 2 pieces of paper.
} 
lighting retrofit, lighting controls across campus, revised bike share program, expanded recycling bins, low flow showerheads, food pulper, student and faculty projects, sustainability coordinator, solar panels, carbon offsets, and purchasing clean energy. The list of projects was developed in consultation with the campus sustainability coordinator, with the coordinator providing the details for the descriptions. ${ }^{6}$ Table 5 gives the ranking of the programs and shows that additional lighting control is the highest priority project for students. This is consistent with the responses to the previous question that showed energy waste as a high priority issue. In fact, 4 out of the 5 most preferred projects deal with energy use. Recycling is ranked as the third most preferred project. Also, low flow showerheads and a revised bike share program receive the worst rankings from students. Interestingly, it seems that the most popular projects require the least active participation from students and programs that may inconvenience students or require student participation are the least popular. Moreover, there is notable heterogeneity in the rankings students assign to the projects. Each of the projects is simultaneously the highest and lowest priority for different students. This heterogeneity is explored in more detail in section 4 .

[Tables 4 and 5 about here]

\subsection{Demographic Data}

Section 2 demonstrated the range of variables that have been shown to affect proenvironmental behavior. This study focuses on demographic and external variables because these are the variables that are most readily observable to university decisionmakers. Students self-report several pieces of demographic information on the survey.

\footnotetext{
${ }^{6}$ Complete descriptions of the projects are given in Appendix A. Some projects have more details because they had been more extensively investigated by the sustainability coordinator. The consequences of the differing details in project descriptions are explored in section 4.2.
} 
These variables include age, gender, racial or ethnic group, whether they are an athlete on a university team, year in school, major, GPA, and personal income.

Home address is one piece of information that students provide on a college application. Institutes of higher education may wonder whether they could use this information to identify which students would be more environmentally focused. If so, it would be relatively straightforward to target the marketing of a green message to these students. This analysis has the benefit of being able to link the survey responses with university-collected data. ${ }^{7}$ The University shared information on each domestic student's zip code, official GPA, race/ethnicity, and gender. GPA, race/ethnicity, and gender are already self-reported on the survey, but this serves as a good validity check on the reliability of the self-reported data. For example, students appear to be mostly truthful when reporting their GPA on the survey. ${ }^{8}$

Several variables are created using the students' zip codes as reported by their permanent addresses given from University records. Using the U.S. Census Bureau Census Region definitions, each student is classified as being from the West, Midwest, Northeast, or South (2013). The political climate from a student's home zip code is proxied with 2012 presidential election results at the county level (Politico, 2012). This political climate variable represents the percentage of the popular vote cast for Barack Obama in the 2012 election. For zip codes entirely contained within one county, this matching is straightforward. For zip codes that span multiple counties, each zip code is matched to a

\footnotetext{
${ }^{7}$ University administration linked the emails from the survey respondents to specific students and then was able to share these linked data with me using anonymous ID's that protected student confidentiality. ${ }^{8}$ The GPA variable is reported in categories with a width of 0.33 on the survey. Taking the midpoint of each category, the average deviation between reported GPA and official GPA is 0.14, with reported GPA being the slightly higher measure. The official GPA data were obtained one semester after the survey, so some slight differences would be expected.
} 
county according to the percentage of the zip code population that falls into a given county. Median household income (measured in \$1000's) at the zip code level comes from the 2008-2012 American Community Survey (ACS) 5-year estimates (2012). The population of the zip code (measured in 1,000's) is included to capture some of the differences between urban and rural upbringings. Finally, information about educational attainment at the zip code level from the 2007-2011 American Community Survey 5-year estimates (2011) is reflected by the percentage of the zip code population 25 years and older with a bachelor's degree or higher. Table 6 provides descriptive statistics for all of these variables.

The final column of Table 6 also shows university wide averages for the non-survey variables. ${ }^{9}$ A comparison between the university wide means and the sample means suggests that the sample composition is relatively representative of the university. As far as magnitude, there are some minor differences in the GPA variable and in the gender composition but nothing to suggest that there is a radically different group self-selecting into the survey compared to the university student population. Treating the university population means as fixed population parameters, one sample mean comparison tests find that mean gpa, gender, and minority status are statistically different for survey participants. ${ }^{10}$ There are no statistical differences in means for region or for any of the zip code characteristics.

[Table 6 about here]

According to the same ACS reports, for the U.S. as a whole, $28.5 \%$ of the population had a BA degree or higher and the median household income was $\$ 53,046$ for

\footnotetext{
${ }^{9}$ Note that this comparison is only possible for non-survey variables because the university population information is not available for the survey variables.

${ }^{10} \mathrm{Gpa}$ and gender are significant at the $1 \%$ level and minority status is significant at the $5 \%$ level.
} 
this same time period. Additionally, $51.4 \%$ of the popular vote was cast for Obama in the 2012 election. Thus, as would be expected, OWU students are coming from areas that are wealthier, more highly educated, and slightly more Republican than the national average. Nevertheless, U.S. News and World Report (2014) categorizes OWU as a "more selective" National Liberal Arts College and it likely shares many characteristics with other institutions found in that ranking.

\subsection{Regression Analysis}

The main data analysis tool utilized in this paper is multiple regression analysis. In multiple regression analysis, the researcher is able to estimate the impact of one variable on the dependent variable (pro-environmental behavior or environmental priority), holding constant all other variables (Kennedy, 2003). The subsequent section describes the empirical models and their associated results.

\section{Regression Results and Discussion}

This section explores heterogeneity in green behavior and in preferences concerning environmental priorities. In section 4.1, a regression model is built for each of the six green behaviors, where the behavior is a function of students' characteristics. Likewise, section 4.2 presents results for priority rankings of the 4 environmental issues and 11 environmental projects.

\subsection{Heterogeneity in Green Behavior}

The appropriate regression model to address heterogeneity in green behavior depends on the nature of the question. The two recycling questions are categorical and ordered; 
therefore, the ordered probit model is appropriate. ${ }^{11}$ The ordered probit model falls within the broader category of multinomial models, which are used when the dependent variable is a discrete outcome that can take one of several values (Cameron and Trivedi, 2005). The ordered probit model utilizes a limited dependent variable where the latent variable, $G B_{i}{ }^{*}$, represents the true level of individual $i$ 's green behavior. $G B_{i}{ }^{*}$ is a function of observable characteristics and an error term:

$G B_{i}^{*}=\beta^{\prime} x_{i}+\varepsilon_{i}$,

where $x_{i}$ is a vector of the observable characteristics of student $i, \beta$ is the vector of parameters to be estimated, and $\varepsilon_{i}$ is an error term assumed to be normally distributed. In this case, the researcher does not observe the level of green behavior $G B_{i}{ }^{*}$ but does observe the ordinal category in which it is reported. For the recycling questions, one observes the reported frequency $F_{i}$, where $F_{i}$ depends on the true level of green behavior as:

$$
F_{i}=\left\{\begin{array}{c}
A Y \text { if } G B_{i}^{*}>k_{4} \\
U Y \text { if } k_{4} \geq G B_{i}^{*}>k_{3} \\
S Y S N \text { if } k_{3} \geq G B_{i}^{*}>k_{2} \\
U N \text { if } k_{2} \geq G B_{i}^{*}>k_{1} \\
A N \text { if } k_{1} \geq G B_{i}^{*}
\end{array}\right\}
$$

where the k's are the cutoffs that determine the intervals of the frequency scale, AY is "always yes", UY is "usually yes", SYSN is "sometimes yes, sometimes no", UN is "usually no", and AN is "always no." Thus, the probability that individual $i$ reports a recycling frequency of "usually no (UN)" is

$\operatorname{Prob}\left(F_{i}=U N\right)=\operatorname{Prob}\left(k_{2} \geq \beta^{\prime} x_{i}+\varepsilon_{i}>k_{1}\right)$

\footnotetext{
${ }^{11}$ For example, an OLS regression would be inappropriate because it would treat the dependent variable as carrying cardinal information, whereas it actually only has ordinal information. An ordered logit model would also be appropriate. The only difference between the ordered logit and the ordered probit model is the assumption on the distribution of the error term in equation 1 (Cameron and Trivedi, 2005).
} 
$=\Phi\left(k_{2}-\beta^{\prime} x_{i}\right)-\Phi\left(k_{1}-\beta^{\prime} x_{i}\right)$,

where $\Phi($.$) is the standard normal c.d.f. Parameter estimation then proceeds via maximum$ likelihood ${ }^{12}$; these results for the recycling behaviors are found in Table 7.

It is possible that the time at college does not have a constant effect on the extent of pro-environmental behavior. For example, it could be the case that there is a large jump in pro-environmental behavior early in college but then no improvements thereafter. Thus, Table 7 shows results from two specifications for both of the recycling behaviors; specification (I) models the year in school as a continuous variable and specification (II) models the year in school as a categorical variable where the omitted comparison year is freshman year. Several significant results emerge across the two recycling behaviors. As would be expected, environmental studies majors are more likely to recycle more frequently. However, this does not show that the environmental studies major actually causes recycling behavior to increase. It could well be that students who are more likely to recycle are also more likely to major in environmental studies because they are interested in environmental issues. This issue of the formal curriculum affecting recycling behavior is discussed in more detail at the end of this subsection. Interestingly, as the year in school increases, students recycle more frequently. This suggests that students are adopting recycling behaviors as they progress through their college careers. Also, white students recycle less frequently than students that fall into one of the other racial categories and male students recycle less frequently than female students. While not significant at conventional levels, there is some weak evidence that students with higher GPA's recycle paper more frequently.

\footnotetext{
${ }^{12}$ See Cameron and Trivedi (2005) for more details of this and the other econometric models.
} 


\section{[Table 7 about here]}

The drawback of the ordered probit model is that the scale of a coefficient is not meaningful. To provide a scale interpretation, average marginal effects for each of the statistically significant independent variables from Table 7 are presented. Note that the marginal effect will be different for each frequency level, $F_{i}$, of the green behavior. Therefore, Tables 8-11 report marginal effects for "always no," "usually no," "usually yes," and "always yes." Tables 8 and 9 report marginal effects for the recycling of materials other than paper and Tables 10 and 11 report marginal effects for recycling of paper. Tables 8 and 10 use results from specification $(I)$ and Tables 9 and 11 use results from specification (II).

[Tables 8-11 about here]

Concentrating first on the results from Tables 8 and 10 where year in school is modeled as continuous (specification I), the year in school has a substantial effect on recycling behavior. Note that this specification constrains the effect of year in college to be constant across years. For each additional year at college, the probability of an individual reporting "always yes" increases by approximately 4 (5) percentage points for recycling paper (materials other than paper). Therefore, on average, a student who is in their fourth year on campus will be approximately 12 percentage points (15 percentage points) more likely to always recycle paper (materials other than paper) compared to a student in their first year on campus. Noting that there are hundreds of students per class, there is a substantial environmental impact due to students learning pro-environmental behavior. 
Specification (II) in Tables 9 and 11 provides evidence that there is an increase in recycling behavior throughout the time at college. However, it does not seem that the effect is constant across years. For example, juniors and seniors display quite similar increases in recycling relative to freshmen in Tables 9 and 11. Relative to a freshman student, a junior or senior student is 13 to 14 percentage points more likely to report "always yes" for recycling materials other than paper and 10 to 11 percentage points more likely to report "always yes" for recycling paper. The magnitudes of the estimated marginal effects for sophomore students are consistent with the sizes of the marginal effects from specification (I) but the estimates are not always statistically significant. Altogether, this suggests that students may take some time to adopt recycling behaviors, and then once they do, subsequent increases are smaller in magnitude. However, this does not change the important qualitative result that seniors are substantially more likely to exhibit recycling behaviors than freshmen.

As seen in Tables 8 and 9, white students are approximately 2 percentage points more likely to report "always no" and approximately 4 percentage points more likely to report "usually no" for recycling other than paper, relative to racial and ethnic minority students. Similarly, for recycling paper (Tables 10 and 11), a white student is 2.5 percentage points more likely to report "always no" and 6 percentage points more likely to report "usually no" compared to racial and ethnic minority students. Tables 10 and 11 also show that a white student is 5 percentage points ( 8 percentage points) less likely than a racial or ethnic minority student to report usually (always) recycling paper.

Tables 8-11 reveal that male students are more likely to report "always no" or "usually no" for recycling and less likely to report "usually yes" or "always yes" for 
recycling. The effect is more statistically significant and of a larger magnitude for recycling paper than for recycling other materials. For recycling paper (Tables 10 and 11), male students are approximately 3 percentage points more likely to report "always no" and 11 percentage points less likely to report "always yes" compared to female students. Likewise, male students are approximately 8 percentage points more likely to report "usually no" and 8 percentage points less likely to report "usually yes" compared to female students for recycling paper. Altogether, there is robust evidence that male students are substantially less prone to recycling than are female students.

The two behaviors that have binary outcomes are examined next; this includes turning off the light the last time the student left a vacant room and participating in green work. The probit model is appropriate here because of the binary outcome (Cameron and Trivedi, 2005). ${ }^{13}$ The specification is

$\operatorname{Prob}(G B=1)=\operatorname{Prob}\left(\beta^{\prime} X_{i}+\varepsilon_{i}>0\right)=\Phi\left(\beta^{\prime} X_{i}\right)$

where $G B$ is the green behavior (turning off the light or participating in green work), $X_{i}$ is a vector of characteristics for individual $i$, and $\beta$ are the parameters to be estimated. As shown in Table 12, the only characteristic that can explain these green behaviors is gender. ${ }^{14}$ Male students are 12 percentage points less likely to turn off the light when leaving a vacant room and also 11 percentage points less likely to participate in green work. However, the green work model is not statistically significant; there is a failure to reject

\footnotetext{
${ }^{13}$ Again, a logit (logistic regression) model could be used in place of a probit model. The choice is largely up to researcher taste with little difference in the estimated average marginal effects. Estimating an OLS regression (a linear probability model) is not preferred because it can result in predicted probabilities outside of the $(0,1)$ interval. However, in practice, results from the linear probability model are usually quite close to the average marginal effects from a probit or logit model (Cameron and Trivedi, 2005). ${ }^{14}$ Majors are omitted from these regressions because some of the majors, such as Environmental Studies, perfectly predict the green behavior.
} 
the null that all characteristics are jointly equal to 0 . This implies that simply asking a question about past or present involvement in green work may not be very informative for universities.

\section{[Table 12 about here]}

The final green behavior examined is arguably the best measure of environmental concern. As previously mentioned, the double-sided printing option in the library has no financial benefit for the student; students are charged the same cost per page regardless of whether they print single or double-sided. Thus, the main reason to print double-sided is to cut down on paper usage. ${ }^{15}$ Students either use the double-sided option in the library or they do not; hence a probit model is specified. Again, two specifications are estimated for Table 13 where $(I)$ treats year in school as continuous and (II) models the years categorically.

\section{[Table 13 about here]}

Holding constant age, each additional year of school is expected to increase the likelihood of a student using the double-sided printing option by 10.1 percentage points (specification $I$ ). Relative to the mean probability of printing double-sided of 0.27 , the marginal effect of an additional year of education is substantial; the magnitude of the marginal effect is approximately $37 \%$ of the mean. For this behavior, the increase in probability is approximately constant across the years as shown in specification (II), although the coefficient for sophomore year is not statistically significant. Students with several majors including social science, humanities, environmental studies, and economics are more likely to use the double-sided printing option. Like the recycling behaviors,

\footnotetext{
${ }^{15}$ It is possible that some students wish to cut down on paper usage in order to have less paper to carry, in addition to any environmental concerns.
} 
minority students and female students are more likely to use the double-sided printing option. On average, a white student is 12 percentage points less likely to use the doublesided printing option compared to a minority student and a male student is 15 percentage points less likely to print double-sided relative to a female student. Interestingly, there is a negative effect of a student coming from a zip code with a higher median income on the probability of using double-sided printing. However, the magnitude of the effect is small; for each $\$ 1000$ increase in zip code median income, there is a 0.25 percentage point decrease in the likelihood of utilizing double-sided printing.

Given the important result that older students report more pro-environmental behaviors, it is worth exploring some explanations. The first plausible explanation could be that it is simply an age effect in that older individuals are more pro-environmental. Since time at school and age are correlated, one could misattribute the age effect to years in school. This is the benefit of multiple regression analysis; one is able to control for age and find the estimated impact of years of college on pro-environmental behavior holding constant age. All of the regressions include age as a control variable and age is never statistically significant at conventional levels. Also, age is most relatively significant in the question on double-sided printing, and there is a negative point estimate on the coefficient for age in those results. Thus, age is reasonably ruled out as the explanation.

The other two explanations are that either increases in pro-environmental behavior are due to formal education or increases in pro-environmental behavior are due to informal education. It is difficult to separate out these two effects given the data but one method is to include interaction effects of major with year in school in the regressions. One can return to the recycling and double-sided printing regressions re-estimate the models including the 
additional interaction terms (major dummies multiplied by year in school). One would presume that students from different majors would experience different degrees of exposure to formal education about the environment. For example, one may expect environmental studies or science majors to acquire more formal education about the environment throughout their time at college. If formal education is causing the increase in pro-environmental behavior, one should expect some of the interaction terms of those majors to be statistically significant and positive. A positive interaction term would say that students in that major increase their pro-environmental behavior more than students outside of that major. However, there is no evidence that this is the case since there are no statistically significant interaction effects in any of the regressions. ${ }^{16}$ This suggests that it is informal education that is causing the increase in pro-environmental behavior throughout a student's time at college.

On the whole, many of the observable characteristics are insignificant in explaining the extent of the various green behaviors. Therefore, universities may find it difficult to predict the level of environmental concern of a prospective student by looking at the demographics of the student's home area. However, the results that minority and older students exhibit more green behavior are stable across the recycling and double printing behaviors. One implication is that there may be an opportunity for institutes of higher education to engage with minority students on environmental issues since they are more likely to exhibit green behaviors with greater frequency. Lastly, the most robust result of all is that females are more environmentally friendly in their behavior than males. On one hand, this implies that female students may be more concerned with a university's

\footnotetext{
${ }^{16}$ These results are found in Appendix B.
} 
environmental performance and universities should pay attention to this. On the other hand, universities concerned with sustainability should recognize that they may need to work harder to persuade male students of its importance.

\subsection{Heterogeneity in Environmental Priorities}

Recall that students ranked 4 broad sustainability concerns of water waste, energy waste, recycling waste, and food waste and 11 specific environmental projects. Regression models are specified for each of the sustainability concerns and environmental projects where the independent variables are the same as those utilized in the models of section 4.1. Here, the dependent variable is a ranking. As a type of categorical outcome, ranked dependent variables are best analyzed with ordered probit (or ordered logit) models. However, in practice, OLS regression is often used to analyze such data when the number of rankings exceeds 5 or 10 . In this case, OLS usually produces quite similar results to the ordered probit model. ${ }^{17}$ Thus, ordered probit results are presented for the 4 sustainability initiatives and OLS results are shown for the 11 specific projects. ${ }^{18}$ Rather than presenting 15 different regression tables, this subsection focuses only on the independent variables that are found to be statistically significant. ${ }^{19}$

Table 14 summarizes the results for the 4 ordered probit regressions. Strikingly, almost none of the explanatory variables are significant; only gender and year in school significantly affect the rankings of 3 of the 4 sustainability concerns. No included variables significantly affect the ranking of food waste. Male students rank water waste as more

\footnotetext{
17 This substantially aids interpretation because an ordered probit model would produce 11 sets of marginal effects for each project, whereas an OLS model produces a single marginal effect.

${ }^{18}$ Ordered probit regressions were also run for the 11 projects and produce similar results. These are available upon request. An examination of the cutoffs $(k ' s)$ of these ordered probit regressions also reveals intervals of fairly consistent width, implying that average OLS marginal effects will be similar.

${ }^{19}$ Full regression results are available upon request.
} 
important and recycling waste as less important compared to female students. For example, a male student is 4.39 percentage points more likely to rank water waste as the highest priority and 6.46 percentage points less likely to rank recycling waste as the highest priority compared to a female student. Students with more years on campus appear to be more concerned with energy waste and less concerned with water waste.

Table 15 shows a summary of the 11 OLS regressions of each environmental project on the set of independent variables. Again, it appears that much of the heterogeneity in preferences is not explained by variables included in the model. The most important explanatory variables are gender and an environmental studies major, but even these are only statistically significant in explaining the ranking of 4 out of the 11 projects. Male students see lighting retrofit, solar panels, and student/faculty projects as more important projects and an expanded recycling program as less important. Environmental studies students appear to have strong preferences in favor of a sustainability coordinator and student/faculty projects and less interest in lighting controls and lighting retrofit. This is sensible because these students would be the very ones working with the sustainability coordinator and on the collaborative student/faculty projects. There are also some geographic differences; relative to a student from the West region of the U.S., Southern students are less interested in lighting controls and purchasing clean energy and Midwestern students are less interested in purchasing clean energy. Also, the food pulper appears to be of more interest to students outside of the West region.

[Tables 14 and 15 about here]

Overall, these results imply that it is not easy to predict which environmental issues or projects students will prefer, even within one specific campus. Perhaps the most useful 
result for university decision-makers is that environmentally minded students may be more attracted to opportunities for collaborative projects and not as impressed with technological innovations to address sustainability, even though the description in Section 3.1 shows that the average student appears to have the opposite preferences. Nonetheless, as shown in Section 3.1, there is considerable heterogeneity in how students rank various environmental projects and sustainability initiatives. Future research on why students differentially prefer certain projects to others would be useful for campus decision-makers trying to identify which projects to make a priority and how to gain support for projects already underway.

There is one potential concern with these rankings results. As discussed in section 3.1 and seen in Appendix A, the environmental project descriptions vary substantially in length and detail. Perhaps students are ranking projects differently based on the descriptions which could bias the results about which projects are preferred. To investigate this further, a rank-ordered logit model is specified. The rank-ordered logit model uses the characteristics of the projects being ranked as explanatory variables for the ranking choices (Beggs et al., 1981). The projects are characterized along 5 dimensions: the number of lines of written text in the project description (1 to 5), whether or not the description stipulates it is a potential project $(1=\mathrm{yes}, 0=\mathrm{no})$, whether or not the project mentions a cost figure ( $1=$ yes, $0=$ no), whether or not the project primarily relates to energy reduction ( $1=y e s$, $0=$ no), and whether or not the project involves off-campus purchases $(1=y e s, 0=n o) .{ }^{20}$ Similar to a conditional logit model, any characteristics of the decision-makers themselves will drop out of the analysis; it is the attributes of the projects that drive the choices in this model (StataCorp, 2011). As seen in Appendix D, these project attributes do significantly

\footnotetext{
${ }^{20}$ Coding for all of these attributes is shown in Appendix C.
} 
impact rankings. However, it is reassuring that the actual project characteristics seem to be relatively more important than the description characteristics. For example, all else equal, each additional line in the description is expected to improve the ranking by 0.08 and stipulating that a project is a potential project is expected to worsen the ranking by 0.19 whereas being a primarily energy related project is expected to improve the ranking by 0.75 and spending money off-campus is expected to worsen the ranking of the project by 0.31. Relative to the mean rankings of the projects shown in Table 5, the magnitudes of the coefficients on the project description characteristics are not large. Therefore, it does not appear that the description characteristics substantially bias the overall ranking results.

\section{Conclusions}

As discussed in section 2, leading models of pro-environmental behavior point to the importance of an individual understanding the behavioral norm or what the morally ideal behavior would be in a situation. According to these theories, learning that others exhibit pro-environmental behaviors or learning that the social benefits of pro-environmental behavior are larger than previously thought should typically lead to an increase in proenvironmental behavior. The college campus is a prime example of a location where extensive learning, both formal and informal, occurs. Yet, relatively little previous work examines the link between time spent on campus and the extent of pro-environmental behavior. The few existing studies focus on Chilean students and do not find a relationship between year of college and extent of pro-environmental behavior. Thus, the main scientific contribution of this paper is the finding that pro-environmental behavior increases with additional time spent on a U.S. residential liberal arts campus; this result is consistent 
with the leading theoretical models. Students in different majors do not increase their proenvironmental behavior at different rates, suggesting that informal learning is driving the change rather than something explicitly taught in the curriculum. This agrees with previous studies that have identified the importance of informal education in driving behavioral change.

Controlling for a range of observable characteristics, there is robust evidence that the scale of behavioral change over the course of a college career is significant. On average, an additional year of college increases the probability of a student reporting that they always recycle by approximately 4 to 5 percentage points. Similarly, an additional year of college increases the probability of a student reporting double-sided printing by approximately 10 percentage points. Moreover, this effect is not driven by the age of the student. The important implication is that universities may play an important role in shaping collective future environmental quality.

Previous literature has also identified several demographic variables including gender and race/ethnicity as being important predictors of pro-environmental behavior. Consistent with prior results, this study finds that females are more likely to engage in green behaviors. Female students are more likely to engage in recycling, double-sided printing, turning off lights in empty rooms, and participating in green organizations or volunteer work. The scale of the effect is substantial; male students are 10 to 15 percentage points less likely, on average, to report these pro-environmental behaviors compared to female students. Contrary to much of the previous literature discussed in section 2, this study finds that minority students are 5 to 10 percentage points more likely to exhibit several pro-environmental behaviors including recycling and double-sided printing. 
The literature analyzing college sustainability initiatives has grown rapidly in recent years. As previously mentioned, this literature tends to focus on describing different models of incorporating sustainability into higher education, determining what leads to success, and identifying roadblocks to adoption. The present paper also contributes to this literature by examining the related issue of which sustainability initiatives are most attractive to students, which has not previously received much quantitative analysis. On a small residential campus, programs related to energy conservation and recycling are much more attractive to students than programs such as a food pulper, a bike share program, or low flow showers. Furthermore, the general student population does not show much interest in setting up a special fund to support collaborative projects between faculty and students related to environmental issues. In general, this study finds that students are more concerned with energy conservation and recycling than other sustainability issues, so colleges and universities may find that expanding efforts in these areas will be more effective in garnering student attention. It remains an open question as to how much an institution's commitment to environmental issues influences students' application and enrollment decisions, and this would be an important area of future research. On a related note, it would be interesting to analyze whether or not students' satisfaction with their institutions' environmental performance affects retention.

The main limitation of this research is that the results stem from one particular university population; as such, they should be interpreted cautiously. Clearly, more work is needed to determine whether or not students follow similar patterns of behavior and have similar environmental preferences at other universities and colleges both within the U.S. and around the world. This study provides some evidence that increases in pro- 
environmental behavior over one's college career is due to factors outside of the formal course of study. However, a limiting factor is that the data do not allow an analysis of what exactly these informal factors are. Future research on what types of college experiences lead to increased pro-environmental behavior would be important. Likewise, this study has not been designed to test between the various models of pro-environmental behavior, although the findings are consistent with models of moral motivation from social psychology and voluntary provision of public goods from economics. Finally, although this study argues that focusing exclusively on college students provides better than typical evidence of the causality of years of college education on pro-environmental behavior, there are limitations to this. For example, there could be selection effects of students dropping out of college that have low pro-environmental tendencies. The remaining students in later years would then, on average, display higher pro-environmental behavior. Thus, more work is needed to firmly establish causality. The ideal study would be a longitudinal in nature where a researcher could follow a sample of students throughout the duration of their college careers, and hence better control for unobservable characteristics. 


\section{References}

2007-2011 American Community Survey 5-Year Estimates. 2011. U.S. Census Bureau.

2008-2012 American Community Survey 5-Year Estimates. 2012. U.S. Census Bureau.

2012 Presidential Election [Politico], [Online] [2014; http://www.politico.com/2012election/map/\#/President/2012/.

Andreoni, J. 1990, "Impure Altruism and Donations to Public Goods: A Theory of Warm-Glow Giving", The Economic Journal, vol. 100, no. 401, pp. 464-477.

Brecard, D., Hlaimi, B., Lucas, S., Perraudeau, Y. \& Salladarre, F. 2009, "Determinants of Demand for Green Products: An Application to Eco-label Demand for Fish in Europe", Ecological Economics, vol. 69, no. 1, pp. 115-125.

Barth, M. \& Rieckmann, M. 2012, "Academic staff development as a catalyst for curriculum change towards education for sustainable development: an output perspective", Journal of Cleaner Production, vol. 26, no. 0, pp. 28-36.

Blok, V., Wesselink, R., Studynka, O. \& Kemp, R. 2015, "Encouraging sustainability in the workplace: a survey on the pro-environmental behaviour of university employees", Journal of Cleaner Production, in press.

Beggs, S., Cardell, S. \& Hausman, J. 1981, "Assessing the potential demand for electric cars", Journal of Econometrics, vol. 17, no. 1, pp. 1-19.

Brekke, K.A., Kverndokk, S. \& Nyborg, K. 2003, "An economic model of moral motivation", Journal of Public Economics, vol. 87, no. 9-10, pp. 1967-1983.

Cameron, A.C. \& Trivedi, P.K. 2005, Microeconometrics: Methods and applications, Cambridge University Press, Cambridge.

Campbell-Arvai, V. 2015, "Food-related environmental beliefs and behaviours among university undergraduates: a mixed-methods study", Int J of Sus in Higher Ed, .

Census Regions and Divisions of the United States [U.S. Census Bureau], [Online] [2013; https://www.census.gov/geo/www/us_regdiv.pdf.

Cerda, A., García, L., Díaz, M., Núñez, C. \& Rojas, J. 2007, "Perfil y Conducta Ambiental de los Estudiantes de la Universidad de Talca, Chile", Panorama Socioeconómico, vol. 25, no. 35, pp. 148-159.

Clark, C.F., Kotchen, M.J. \& Moore, M.R. 2003, "Internal and external influences on pro-environmental behavior: Participation in a green electricity program", Journal of Environmental Psychology, vol. 23, no. 3, pp. 237-246. 
College Hopes and Worries Results [The Princeton Review], [Online] [2014;

http://www.princetonreview.com/college-hopes-worries.aspx.

Dautremont-Smith, J. 2009, How do campus sustainability initiatives affect college admissions?, Association for the Advancement of Sustainability in Higher Education (AASHE), http://www.aashe.org/blog/how-do-campus-sustainability-initiativesaffect-college-admissions.

De Silva, D.G. \& Pownall, R.A.J. 2014, "Going green: does it depend on education, gender or income?" Applied Economics, vol. 46, no. 5, pp. 573-586.

Digby, C.L.B. 2013, "The Influences of Socio-demographic Factors, and Non-formal and Informal Learning Participation on Adult Environmental Behaviors", International Electronic Journal of Environmental Education, vol. 3, no. 1, pp. 37-55.

Eisler, A.D., Eisler, H. \& Yoshida, M. 2003, "Perception of human ecology: crosscultural and gender comparisons", Journal of Environmental Psychology, vol. 23, no. 1 , pp. 89-101.

Ek, K. \& Söderholm, P. 2008, "Norms and economic motivation in the Swedish green electricity market", Ecological Economics, vol. 68, no. 1-2, pp. 169-182.

Fernández-Manzanal, R., Rodríguez-Barreiro, L. \& Carrasquer, J. 2007, "Evaluation of environmental attitudes: Analysis and results of a scale applied to university students", Science Education, vol. 91, no. 6, pp. 988-1009.

Ferreira, S. \& Moro, M. 2013, "Income and preferences for the environment: evidence from subjective well-being data", Environment and Planning A, vol. 45, no. 3, pp. $650-667$.

Harbaugh, W.T. 1998, "What do donations buy?: A model of philanthropy based on prestige and warm glow", Journal of Public Economics, vol. 67, no. 2, pp. 269-284.

Heyl, M., Moyano Díaz, E. \& Cifuentes, L. 2013, "Environmental attitudes and behaviors of college students: a case study conducted at a chilean university", Revista Latinoamericana de Psicología, vol. 45, no. 3, pp. 487-500.

Holländer, H. 1990, "A Social Exchange Approach to Voluntary Cooperation", The American Economic Review, vol. 80, no. 5, pp. 1157-1167.

Hopkinson, P., Hughes, P. \& Layer, G. 2008, "Sustainable graduates: linking formal, informal and campus curricula to embed education for sustainable development in the student learning experience", Environmental Education Research, vol. 14, no. 4, pp. $435-454$. 
Johnson, C.Y., Bowker, J.M. \& Cordell, H.K. 2004, "Ethnic Variation in Environmental Belief and Behavior: An Examination of the New Ecological Paradigm in a Social Psychological Context", Environment and Behavior, vol. 36, no. 2, pp. 157-186.

Jones, R.E. 1998, "Black concern for the environment: Myth versus reality", Society \& Natural Resources, vol. 11, no. 3, pp. 209-228.

Kennedy, P. 2003, A guide to econometrics, Fifth edition. Cambridge: MIT Press.

Klineberg, S.L., McKeever, M. \& Rothenbach, B. 1998, "Demographic predictors of environmental concern: It does make a difference how it's measured", Social Science Quarterly, vol. 79, no. 4, pp. 734-753.

Kollmuss, A. \& Agyeman, J. 2002, "Mind the Gap: Why do people act environmentally and what are the barriers to pro-environmental behavior?", Environmental Education Research, vol. 8, no. 3, pp. 239-260.

Kristrom, B. \& Riera, P. 1996, "Is the income elasticity of environmental improvements less than one?", Environmental and Resource Economics, vol. 7, no. 1, pp. 45-55.

Larrán Jorge, M., Herrera Madueño, J., Calzado Cejas, M.Y. \& Andrades Peña, F.J. 2015, "An approach to the implementation of sustainability practices in Spanish universities", Journal of Cleaner Production, in press.

Levine, D.S. \& Strube, M.J. 2012, "Environmental Attitudes, Knowledge, Intentions and Behaviors Among College Students", The Journal of social psychology, vol. 152, no. 3, pp. 308-326.

Levy, B.L.M. \& Marans, R.W. 2012, "Towards a campus culture of environmental sustainability", Int J of Sus in Higher Ed, vol. 13, no. 4, pp. 365-377.

Lidgren, A., Rodhe, H. \& Huisingh, D. 2006, "A systemic approach to incorporate sustainability into university courses and curricula", Journal of Cleaner Production, vol. 14, no. 9-11, pp. 797-809.

Lozano, R. 2006, "Incorporation and institutionalization of SD into universities: breaking through barriers to change", Journal of Cleaner Production, vol. 14, no. 9-11, pp. 787-796.

Lozano, R., Ceulemans, K., Alonso-Almeida, M., Huisingh, D., Lozano, F.J., Waas, T., Lambrechts, W., Lukman, R. \& Hugé, J. 2015, "A review of commitment and implementation of sustainable development in higher education: results from a worldwide survey", Journal of Cleaner Production, in press.

Meyer, A. 2015, "Does education increase pro-environmental behavior? Evidence from Europe", Ecological Economics, vol. 116, no. 0, pp. 108-121. 
National Liberal Arts College Rankings [U.S. News \& World Report], [Online] [2014; http://colleges.usnews.rankingsandreviews.com/best-colleges/rankings/nationalliberal-arts-colleges.

Ramos, T.B., Caeiro, S., van Hoof, B., Lozano, R., Huisingh, D. \& Ceulemans, K. 2015, "Experiences from the implementation of sustainable development in higher education institutions: Environmental Management for Sustainable Universities", Journal of Cleaner Production, in press.

Rege, M. 2004, "Social Norms and Private Provision of Public Goods", Journal of Public Economic Theory, vol. 6, no. 1, pp. 65-77.

Schmitt-Figueiró, P. \& Raufflet, E. 2015, "Sustainability in higher education: a systematic review with focus on management education", Journal of Cleaner Production, in press.

Schultz, P.W., Oskamp, S. \& Mainieri, T. 1995, "Who recycles and when? A review of personal and situational factors", Journal of Environmental Psychology, vol. 15, no. 2, pp. 105-121.

Schwartz, S.H. 1970, "Elicitation of moral obligation and self-sacrificing behavior: An experimental study of volunteering to be a bone marrow donor", Journal of personality and social psychology, vol. 15, no. 4, pp. 283-293.

Schwartz, S.H. 1973, "Normative explanations of helping behavior: A critique, proposal, and empirical test", Journal of experimental social psychology, vol. 9, no. 4, pp. 349364.

Schwartz, S.H. 1977, "Normative influences on altruism" in , ed. L. Berkowitz, NY Academic Press, , pp. 271, 221-271, 221.

Scott, D. \& Willits, F.K. 1994, "Environmental Attitudes and Behavior: A Pennsylvania Survey", Environment and Behavior, vol. 26, no. 2, pp. 239-260.

StataCorp. 2011. Stata 12 Base Reference Manual. College Station, TX: Stata Press.

Stern, P.C., Dietz, T. \& Kalof, L. 1993, "Value Orientations, Gender, and Environmental Concern", Environment and Behavior, vol. 25, no. 5, pp. 322-348.

Torgler, B. \& García-Valiñas, M.A. 2007, "The determinants of individuals' attitudes towards preventing environmental damage", Ecological Economics, vol. 63, no. 2-3, pp. 536-552.

Turaga, R.M.R., Howarth, R.B. \& Borsuk, M.E. 2010, "Pro-environmental behavior", Annals of the New York Academy of Sciences, vol. 1185, no. 1, pp. 211-224. 
Vicente-Molina, M.A., Fernández-Sáinz, A. \& Izagirre-Olaizola, J. 2013, "Environmental knowledge and other variables affecting pro-environmental behaviour: comparison of university students from emerging and advanced countries", Journal of Cleaner Production, vol. 61, no. 0, pp. 130-138.

Viscusi, W.K., Huber, J. \& Bell, J. 2011, "Promoting Recycling: Private Values, Social Norms, and Economic Incentives", American Economic Review, vol. 101, no. 3, pp. 65-70.

Zabel, J.E. \& Kiel, K.A. 2000, "Estimating the Demand for Air Quality in Four U.S. Cities", Land Economics, vol. 76, no. 2, pp. 174-194.

Zelezny, L.C., Chua, P. \& Aldrich, C. 2000, "New Ways of Thinking about Environmentalism: Elaborating on Gender Differences in Environmentalism", Journal of Social Issues, vol. 56, no. 3, pp. 443-457.

Zilahy, G. \& Huisingh, D. 2009, "The roles of academia in Regional Sustainability Initiatives", Journal of Cleaner Production, vol. 17, no. 12, pp. 1057-1066.

Zsóka, Á., Szerényi, Z.M., Széchy, A. \& Kocsis, T. 2013, "Greening due to environmental education? Environmental knowledge, attitudes, consumer behavior and everyday pro-environmental activities of Hungarian high school and university students", Journal of Cleaner Production, vol. 48, no. 0, pp. 126-138.

Zube, E.H. \& Pitt, D.G. 1981, "Cross-cultural perceptions of scenic and heritage landscapes", Landscape Planning, vol. 8, no. 1, pp. 69-87. 


\section{Appendix A: Project Descriptions}

Complete lighting retrofit: this is changing out older lighting fixtures and lamps to more energy efficient lamps and bulbs. This would reduce campus electricity usage, which in turn reduces utility costs and emissions of air pollutants. A project to change approximately $25 \%$ of the lights on campus would cost around $\$ 50,000$.

Lighting controls across campus: Occupancy sensors can reduce electricity usage by $10-60 \%$ in a given areas depending on location and usage; bathrooms, storage rooms, etc are seldom utilized and sensors can save upwards of 50\%.

Revised bike share program: Provide bikes on campus and allow students to borrow; aiming to decrease car use, and the associated pollution.

Expanded recycling bins: We have a few hundred indoor bins across campus, but we require double this number to make the program more effective. A $15 \%$ increase in recycling is estimated if we can increase accessibility of the recycling bins.

Low flow showerheads: There are more than 500 showers in the residence buildings on campus. If we change these showerheads to the low flow showerheads, it has a cost of approximately $\$ 18,000$, but a saving conservatively of $\$ 17,000$ per year on water (not including savings to heat water).

Food pulper: Food pulper chops up and dewaters food waste to reduce weight by volume $80-85 \%$; weight of shipping food waste is the major impediment to composting here on campus. This would make a composting program viable. This would cost about $\$ 50,000$. Student and faculty projects: set up a special fund to support student and faculty sustainability projects

Sustainability Coordinator: we currently have a sustainability coordinator on campus under a grant-funded position. The grant provides funding for one more year. After this time, we will need to identify alternative sources of funding if we want to continue the position. The sustainability coordinator manages the environmental projects and identifies projects that will maximize cost savings and environmental benefits.

Solar Panels: (potential project) Purchase and install solar panels to generate electricity. Carbon Offsets: (potential project) Purchase carbon offsets from an off-campus supplier. Purchasing Clean Energy: (potential project) Purchase energy generated from wind or solar sources. 


\section{Appendix B: Major Interaction Regression Results}

Table B1: Major Interaction Results

\begin{tabular}{|c|c|c|c|}
\hline & Recycle Other than Paper & Recycle Paper & Double Printing \\
\hline \multicolumn{4}{|l|}{ Self-Reported on Survey } \\
\hline \multirow[t]{2}{*}{ Age } & 0.018 & 0.020 & -0.0415 \\
\hline & $(0.0391)$ & $(0.0386)$ & $(0.0282)$ \\
\hline \multirow[t]{2}{*}{ Year in School } & 0.175 & $0.241 *$ & $0.183 * * *$ \\
\hline & $(0.138)$ & $(0.136)$ & $(0.062)$ \\
\hline \multicolumn{4}{|l|}{ Majors } \\
\hline \multirow[t]{2}{*}{ Social Science } & 0.324 & 0.311 & $0.273 *$ \\
\hline & $(0.331)$ & $(0.327)$ & $(0.142)$ \\
\hline \multirow[t]{2}{*}{ Science } & -0.156 & 0.198 & $0.319 *$ \\
\hline & $(0.334)$ & $(0.330)$ & $(0.147)$ \\
\hline \multirow[t]{2}{*}{ Humanities } & 0.524 & 0.288 & $0.297 * *$ \\
\hline & $(0.378)$ & $(0.372)$ & $(0.147)$ \\
\hline \multirow[t]{2}{*}{ Arts } & 0.172 & 0.0583 & 0.215 \\
\hline & $(0.429)$ & $(0.421)$ & $(0.183)$ \\
\hline \multirow[t]{2}{*}{ Sports } & 0.922 & 0.180 & 0.332 \\
\hline & $(0.840)$ & $(0.835)$ & $(0.370)$ \\
\hline \multirow[t]{2}{*}{ Environmental Studies } & -0.0314 & 0.702 & -2.41 \\
\hline & $(0.965)$ & $(0.891)$ & $(72.07)$ \\
\hline \multirow[t]{2}{*}{ Economics/Business } & -0.589 & -0.171 & $0.430 * *$ \\
\hline & $(0.523)$ & $(0.523)$ & $(0.212)$ \\
\hline \multicolumn{4}{|l|}{ Major Interactions } \\
\hline \multirow[t]{2}{*}{ Year x Social Science } & -0.101 & -0.122 & -0.0769 \\
\hline & $(0.133)$ & $(0.131)$ & $(0.0536)$ \\
\hline \multirow[t]{2}{*}{ Year x Science } & 0.126 & 0.023 & -0.0783 \\
\hline & $(0.139)$ & $(0.137)$ & $(0.0565)$ \\
\hline \multirow[t]{2}{*}{ Year x Humanities } & -0.201 & -0.077 & -0.0758 \\
\hline & $(0.140)$ & $(0.138)$ & $(0.0524)$ \\
\hline \multirow[t]{2}{*}{ Year x Arts } & -0.0132 & -0.0493 & -0.0783 \\
\hline & $(0.174)$ & $(0.170)$ & $(0.069)$ \\
\hline \multirow[t]{2}{*}{ Year x Sports } & -0.452 & -0.214 & -0.0947 \\
\hline & $(0.282)$ & $(0.280)$ & $(0.120)$ \\
\hline \multirow[t]{2}{*}{ Year x Environmental Studies } & 0.564 & 0.265 & 1.363 \\
\hline & $(0.453)$ & $(0.399)$ & $(36.04)$ \\
\hline \multirow[t]{2}{*}{ Year x Economics/Business } & 0.095 & -0.0258 & -0.0804 \\
\hline & $(0.182)$ & $(0.180)$ & $(0.0707)$ \\
\hline \multicolumn{4}{|c|}{ Personal Characteristics Obtained from University Records } \\
\hline \multirow[t]{2}{*}{ White } & $-0.463 * * *$ & $-0.417 * * *$ & $-0.123 * *$ \\
\hline & $(0.158)$ & $(0.153)$ & $(0.0542)$ \\
\hline \multirow[t]{2}{*}{ Male } & $-0.397 * * *$ & $-0.514 * * *$ & $-0.149 * * *$ \\
\hline & $(0.111)$ & $(0.110)$ & $(0.0437)$ \\
\hline log likelihood & -634.24 & -669.85 & -258.61 \\
\hline Model p-value & 0.000 & 0.000 & 0.000 \\
\hline
\end{tabular}




\section{Appendix C: Project Attribute Coding}

Table C1: Coding of Variables for Rank-Ordered Logit Regression

\begin{tabular}{|c|c|c|c|c|c|}
\hline & \multicolumn{3}{|c|}{ Description Characteristics } & \multicolumn{2}{|c|}{ Project Characteristics } \\
\hline & \# Lines & Cost Figure & Potential & Energy Reduction & Off-Campus \\
\hline Lighting & & & & & \\
\hline Controls & 3 & 1 & 0 & 1 & 0 \\
\hline Lighting & & & & & \\
\hline Retrofit & 4 & 0 & 0 & 1 & 0 \\
\hline Recycling & 3 & 0 & 0 & 0 & 0 \\
\hline Solar panels & 1 & 0 & 1 & 1 & 0 \\
\hline Purchasing & & & & & \\
\hline Clean Energy & 1 & 0 & 1 & 1 & 1 \\
\hline Sustainability & & & & & \\
\hline Coordinator & 5 & 0 & 0 & 0 & 0 \\
\hline Food Pulper & 3 & 1 & 0 & 0 & 0 \\
\hline Carbon Offsets & 1 & 0 & 1 & 1 & 1 \\
\hline Student/Faculty & & & & & \\
\hline Projects & 1 & 0 & 0 & 0 & 0 \\
\hline Low Flow & & & & & \\
\hline Showers & 4 & 1 & 0 & 0 & 0 \\
\hline Bike Share & & & & & \\
\hline Program & 2 & 0 & 0 & 0 & 0 \\
\hline
\end{tabular}




\section{Appendix D: Rank-Ordered Logit Results}

Table D1: Rank-Ordered Logit Results.

I.

Description Characteristics

\# Lines

$-0.0835^{* * *}$

(0.0156)

Cost Figure

$0.262 * * *$

(0.0410)

Potential Project $\quad 0.186 * *$

(0.0758)

Project Characteristics

Energy Reduction $\quad-0.746 * * *$

$(0.0453)$

Off-campus Spending $\quad 0.307 * * *$

(0.0539)

Observations

5665

Number of Individuals

515

Model p-value

0.000

Note: Dependent variable is project ranking where $1=$ highest priority, $11=$ lowest priority.

Standard errors in parentheses are clustered at the individual level.

** Significant at 5\%, *** Significant at $1 \%$ 